\title{
IMPLEMENTASI PENDIDIKAN KARAKTER DALAM PEMBELAJARAN IPS DI SEKOLAH DASAR (SD PB SOEDIRMAN, SD N DUKUH 09 PAGI, SD N SUSUKAN 06)

\author{
Agustina Tri Wijayanti \\ Laely Armyati
}

Pendidikan IPS FIS UNY, Pendidikan Sejarah FKIP UHAMKA

Email : agustina1044@gmail.com, Hp. 085292087344

\begin{abstract}
Abstrak
Pembelajaran IPS merupakan proses pembelajaran yang mempelajari manusia yang bertujuan untuk membuat siswa memiliki perilaku yang baik, keterampilan yang baik, sikap yang baik dan pengetahuan yang baik. Pendidikan karakter merupakan bagian dari studi ilmu sosial. Tujuan dari penelitian ini adalah: (1) untuk mengetahui pemahaman guru tentang pendidikan karakter, (2) untuk mengetahui kemampuan guru dari mengintegrasikan pendidikan karakter dalam rencana, tindakan dan evaluasi, (3) untuk mengetahui kesulitan guru untuk pelaksanaan pendidikan karakter di sekolah dasar. Penelitian ini menggunakan metode deskriptif kualitatif. Hasilnya adalah (1) guru memiliki pemahaman yang baik tentang pendidikan karakter, (2) guru terintegrasi pendidikan karakter dalam rencana, tindakan dan evaluasi, tapi itu tidak maksimal dalam tindakan dan evaluasi, (3) kesulitan guru adalah memunculkan nilai-nilai karakter dalam sosial studi pembelajaran, terutama dalam peroses pembelajaran.
\end{abstract}

Kata Kunci: Pendidikan karakter, Pembelajaran IPS, belajar 


\begin{abstract}
Social learning of social studies of human to make the students behavior, skills, attitude and knowledge. Character education is part of social sciences. The purpose of this study was to determine the teachers' understanding of character education, the ability of teachers to integrate character education in the plan, action and evaluation, the difficulty teachers for the implementation of character education in elementary schools. This research uses descriptive qualitative method. The result is (1) the teacher has a good understanding of character education, (2) integrated character education teachers in planning, action and evaluation, but it is not optimal in action and evaluation, (3) the difficulty of teachers is bring the values of the social character the study of learning, especially in learning process.
\end{abstract}

Keywords: character education, social learning, learning

\title{
Pendahuluan
}

Tujuan Pendidikan Nasional yang tercantum dalam UU No. 20 Tahun 2003 menyatakan bahwa tujuan pendidikan adalah mewujudkan suasana belajar dan proses pembelajaran agar peserta didik secara aktif dapat mengembangkan potensi dirinya untuk memiliki kekuatan spiritual keagamaan, pengendalian diri, kepribadian, kecerdasan, akhlak mulia serta keterampilan yang diperlukan dirinya, masyarakat, bangsa dan Negara. Sehubungan dengan tujuan pendidikan tersebut, pemerintah berupaya untuk meningkatkan kualitas pendidikan agar dapat menghasilkan sumber daya manusia yang cerdas, berkualitas, berkarakter dan berbudaya. Peningkatan kualitas sumber daya manusia dapat ditempuh melalui perbaikan sistem pendidikan yang mengarah pada pembentukan karakter siswa sejak tingkat pra-sekolah sampai perguruan tinggi. Pembentukan karakter sebagai upaya meningkatkan perilaku siswa dilaksanakan secara berkesinambungan yang melibatkan aspek knowledge, feeling, dan acting (Tadkiroatun Musfiroh, 2008: 31). 
Pendidikan karakter saat ini tengah menjadi sorotan dari berbagai kalangan. Rendahnya kualitas moral terutama masyarakat di Jakarta, yang dimunculkan dengan berbagai kriminalitas, asusila, hingga pembunuhan yang dilakukan oleh anak remaja, menumbuhkan pertanyaan-pertanyaan kepada institusi sekolah selaku wadah yang dipercaya untuk mendidik anak-anak tersebut. Institusi sekolah tidak akan berjalan dengan baik tanpa adanya elemen-elemen pendukung yang memiliki pandangan yang sama tentang implementasi pendidikan karakter di sekolah. Maka, guru sebagai salah satu elemen, memiliki peranan yang sangat penting untuk menerapkan pendidikan karakter dalam kegiatan pembelajarannya, sebagai upaya menanggulangi krisis moralitas yang menimpa remaja-remaja di Jakarta. Penelitian ini dimaksudkan untuk melihat dan menganalisis langkah-langkah guru dalam mengimplementasikan pendidikan karakter dalam kegiatan pembelajaran IPS.

Berdasarkan latar belakang masalah, maka rumusan masalah dalam penelitian ini adalah sebagai berikut.

1. Bagaimanakah pemahaman guru mengenai pendidikan karakter dalam kegiatan pembelajaran IPS?

2. Bagaimanakah guru mengintegrasikan pendidikan karakter dalam tahap perencanaan, pelaksanaan, dan evaluasi pembelajaran?

3. Apakah kendala yang dihadapi guru untuk mengimplementasikan pendidikan karakter dalam pembelajaran IPS SD?

\section{Pendidikan Karakter}

Ryan (1999: 5) berpendapat bahwa "good character is about knowing the good, loving the good and doing the good". Artinya bahwa karakter yang baik adalah tentang suatu pengetahuan yang 
baik, kasih sayang, cinta kasih yang baik dan melakukan atau bertindak yang baik. Pendapat tersebut diperkuat oleh Lickona (1992: 51) yang menjalaskan tentang pengertian dan menawarkan satu cara memaknai karakter dalam pembelajaran, sebagai berikut:

"Character consist of operative values, values in action. Character conceived has three interrelated parts: moral knowing, moral feeling and moral behavior. Good character consists of knowing the good, desiring the good and doing the good-habits of the mind, habits of the heart and habits of action".

Pernyataan di atas dapat dijelaskan bahwa karakter terdiri dari nilai-nilai tindakan. Karakter yang dipahami mempunyai tiga komponen saling berhubungan yaitu pengetahuan moral, perasaan moral dan perilaku moral. Karakter yang baik terdiri dari pengetahuan yang baik, menginginkan yang baik dan melakukan kebiasaan yang baik pula dari pikiran, kebiasaan dan tindakan. Lickona (1992: 53) mendefinisikan tiga komponen dalam membentuk karakter yang baik, yaitu:

Aspek dari tiga komponen karakter adalah: Moral knowing yaitu 1) kesadaran moral (moral awarenees), 2) mengetahui nilai moral (knowing moral values), 3) perspective taking, 4) penalaran moral (moral reasoning) 5) membuat keputusan (decision making) 6) pengetahuan diri (self knowledge). Unsur moral knowing mengisi ranah kognitif siswa. Sedangkan moral feeling, enam hal yang merupakan aspek dari emosi yang harus mampu dirasakan oleh seseorang untuk menjadi manusia berkarakter yaitu: 1) nurani (conscience), 2) penghargaan diri (self esteem), 3) empati (empathy), 4) cinta kebaikan, kasih sayang (loving the good), 5) kontrol diri (self control) dan 6) kerendahan hati (humility). Moral actions merupakan perbuatan atau tindakan moral dari dua komponen karakter lainnya. Untuk memahami apa yang mendorong 
seseorang untuk berbuat (act morally) maka harus dilihat tiga aspek lain dari karakter yaitu kompetensi (competence), keinginan (will), dan kebiasaan (habit).

\section{Pengertian IPS}

National Council for Social Studies (NSCC) mendefinisikan Ilmu Pengetahuan Sosial sebagai berikut:

"Social studies as "the integrated study of the social science and humanities to promote civic competence". Within the school program, social studies provides coordinated, systematic, study drawing upon such disciplines as anthropology, archeology, economics, geography, law, philosophy, political science, psychology, religion and sociology, as well as appropriate content from the humanities, mathematic and natural sciences. (NCSS, 2006:1)"

Melalui pembelajaran Ilmu Pengetahuan Sosial, siswa diajarkan untuk menjadi warga Negara Indonesia yang baik dan penuh kedamaian. Ilmu Pengetahuan Sosial diperlukan bagi keberhasilan transisi kehidupan menuju pada kehidupan yang lebih dewasa dalam upaya membentuk karakter bangsa yang sesuai dengan prinsip dan semangat nasional. Dengan demikian para siswa dalam pembelajaran IPS terlatih untuk menyelesaikan persoalan sosial dengan pendekatan secara holistik dan terpadu dari berbagai sudut pandang.

Proses pembelajaran karakter dalam pembelajaran IPS lebih diarahkan pada aspek pengetahuan, ketrampilan dan perilaku, seperti yang diungkapkan Barth (1990: 254) terdapat tiga aspek dalam pembelajaran yang harus dicapai yaitu; “a) knowledge, which is a body of fact and principles; b) skill, which is acquiring an ability through experience or training; c) attitude, which is one's opinion, feeling or mental set as demonstrated by one's action”. Pendidikan karakter merupakan proses untuk membentuk, menumbuhkan, mengembangkan dan mendewasakan kepribadian anak menjadi pribadi yang bijaksana dan bertanggung jawab 
melalui pembiasaan pikiran, hati dan tindakan secara berkesinambungan yang hasilnya dapat terlihat dalam proses pembelajaran serta tindakan nyata sehari-hari baik di sekolah maupun di masyarakat.

\section{Metode Penelitian}

Penelitian ini menggunakan metode kualitatif deskriptif. Menurut Sutopo (2006: 139) sifat penelitian kualitatif deskriptif berarti penelitian kualitatif yang selalu menyajikan temuannya dalam bentuk deskripsi kalimat yang rinci, lengkap, dan mendalam mengenai proses mengapa dan bagaimana sesuatu terjadi. Dengan menggunakan penelitian kualitatif deskriptif, peneliti akan mampu menangkap berbagai informasi kualitatif dengan deskripsi teliti (Sutopo, 2006: 227).

Teknik pengumpulan data yang digunakan dalam penelitian ini adalah wawancara mendalam, observasi langsung berperan pasif, dan analisis dokumen. Penelitian menggunakan teknik trianggulasi data dan trianggulasi metode.

Analisis yang dilakukan pada penelitian ini menggunakan analisis model interaktif, yaitu teknik analisis yang aktivitasnya dilakukan dalam bentuk interaktif dengan proses pengumpulan data sebagai proses siklus. Setelah pengumpulan data, peneliti hanya bergerak dalam tiga komponen analisis. Aktivitas tersebut dilakukan, baik pada analisis setiap unit kasus maupun antarkasus untuk memahami perbedaan dan persamaannya.

\section{Hasil Penelitian dan Pembahasan}

\section{Pemahaman Guru mengenai Pendidikan Karakter dalam Pembelajaran IPS}

Pemahaman awal mengenai pendidikan karakter, dilihat melalui sumber informasi guru. Di SD Dukuh 09, sumber informasi adalah kepala sekolah, dan kemudian guru melakukan 
diskusi dengan rekan sejawat. Hal ini tampak dari hasil wawancara dengan guru yang diwakili bu Eka yang mengampu kelas 4, beliau mengetahui mengetahui pendidikan karakter melalui kepala sekolah, kemudian tidak lama ada wacana implementasi pendidikan karakter di sekolah.

Mengenai tujuan dan fungsi pendidikan karakter, dipahami guru (Wawancara tanggal 28 Mei 2012) sebagai upaya untuk membentuk peserta didik yang sesuai dengan 18 nilai karakter dalam panduan pendidikan karakter, tapi guru juga tidak menutup kemungkinan untuk menambahkan nilai karakter lain yang bisa menjadi counter positif bagi perkembangan peserta didik.

Mengenai pelaksanaan pendidikan karakter dalam pembelajaran IPS, guru menyatakan perlu adanya integrasi nilainilai karakter dalam pembelajaran IPS. Hal ini terkait dengan tujuan IPS yaitu membentuk peserta didik yang mampu bersosialisasi dengan baik di masyarakat. Selain itu, nilai-nilai karakter sangat cocok dengan materi-materi yang ada dalam pelajaran IPS di SD, seperti gotong royong, tolong menolong, dsb. Tetapi, seharusnya implementasi pendidikan karakter tidak hanya dalam satu mata pelajaran saja, tetapi di semua mata pelajaran.

Pengkajian mengenai pemahaman guru SDS PB Soedirman dilakukan melalui wawancara. Guru SDS PB Soedirman telah memiliki pemahaman yang baik mengenai pendidikan karakter dan upaya untuk implementasinya dalam setiap mata pelajaran. Guru juga memberikan komentar positif terhadap upaya pemerintah untuk memformalkan pendidikan karakter di sekolah. Guru menjelaskan bahwa pendidikan karakter merupakan penanaman nilai-nilai karakter pada siswa melalui penyadaran diri. Pendidikan karakter tidak hanya dilakukan selama kegiatan 
pembelajaran, tetapi juga di luar kegiatan pembelajaran dan setiap saat.

Mengenai relevansi pendidikan karakter dengan pembelajaran IPS, guru menyatakan bahwa ada keterkaitan antara IPS dengan pendidikan karakter. Disinggung mengenai pemahamannya dalam strategi integrasi pendidikan karakter dalam pembelajaran IPS, Guru SDS PB Soedirman menyatakan bahwa pelaksanaan pendidikan karakter, seharusnya tidak hanya dilakukan pada mata pelajaran yang terkait dengan ilmu sosial atau agama, tetapi juga pada setiap mata pelajaran. Pendidikan karakter di sekolah juga tidak akan berhasil jika guru tidak memberi keteladanan, pembiasaan, dan penyadaran diri kepada siswa. Selain itu, perlunya dukungan dari orang tua, karena seringkali sikap anak di sekolah dan di rumah berbeda, maka perlu adanya komunikasi yang baik antara guru dan orang tua murid.

Sedangkan guru SD N Susukan 06 memahami secara realistis mengenai pendidikan karakter. Pemahaman awal mengenai pendidikan karakter, dilihat melalui sumber informasi guru. Guru kelas 4 menjelaskan bahwa pertama mengenal tentang pendidikan karakter melalui teman-teman guru, kemudian tidak lama ada wacana implementasi pendidikan karakter di sekolah yang disampaikan oleh kepala sekolah. Sebagai tindak lanjut dari wacana tersebut, kepala sekolah mensosialisasikan kepada guruguru bahwa pembelajaran harus diintegrasikan dengan nilai-nilai karakter tersebut. Tapi sampai saat ini saya belum pernah mengikuti pelatihan atau workshop tentang implementasi pendidikan karakter dalam pembelajaran.

Mengenai relevansi pendidikan karakter dengan pembelajaran IPS, guru menyatakan bahwa ada keterkaitan antara IPS dengan pendidikan karakter. Pembelajaran IPS efektif untuk 
mengintegrasikan nilai-nilai karakter karena materi yang ada pada pelajaran IPS tidak jauh-jauh dengan kehidupan siswa sehari-hari. Pelajaran IPS memuat materi tentang lingkungan masyarakat, permasalahan sosial, materi tersebut yang harus dipahami oleh siswa sehingga ketika siswa berada di dalam lingkungan masyarakat dapat secara cepat menghadapi dan menyelesaikan berbagai persoalan yang terjadi dalam masyarakat. Memang tidak hanya di dalam kelas tetapi di luar kelas pun juga bisa untuk mengembangkan nilai karakter yang diharapkan.

\section{Integrasi Pendidikan Karakter dalam Pembelajaran IPS}

Pengkajian mengenai integrasi pendidikan karakter dalam pembelajaran IPS, meliputi pengamatan pada dua tahap, yaitu persiapan dan pelaksanaan pembelajaran. Tahap persiapan meliputi penyusunan RPP dan Silabus guru, sedangkan tahap pelaksanaan adalah proses kegiatan belajar mengajar di kelas.

Observasi pembelajaran IPS di kelas 4 SDS PB Soedirman, pada tahap persiapan, guru telah menyusun silabus dan RPP dengan mencantumkan karakter yang diharapkan. Guru menyampaikan karakter disiplin, rasa hormat, perhatian, tekun, jujur, dan ketelitian. Penulisan karakter dalam RPP, merupakan langkah awal untuk melakukan implementasi pendidikan karakter dalam pembelajaran IPS. Selanjutnya, pengkajian melihat kegiatan awal, kegiatan inti, dan kegiatan penutup dalam RPP yang disusun guru.

Tabel 1. Nilai karakter dalam pembelajaran IPS di kelas 4 SDS PB Soedirman

\begin{tabular}{|c|c|c|c|}
\hline Tahap & Kegiatan Guru & Kegiatan Siswa & $\begin{array}{c}\text { Nilai } \\
\text { Karakter }\end{array}$ \\
\hline $\begin{array}{l}\text { Kegiatan } \\
\text { Awal }\end{array}$ & $\begin{array}{l}\text { Guru mengucap } \\
\text { salam dan } \\
\text { berdoa } \\
\text { Guru } \\
\text { mengkondisikan }\end{array}$ & $\begin{array}{l}\text { Siswa menjawab } \\
\text { salam dan berdoa } \\
\text { Siswa } \\
\text { mengkondisikan } \\
\text { diri untuk siap }\end{array}$ & $\begin{array}{l}\text { Religius, } \\
\text { tanggung } \\
\text { jawab }\end{array}$ \\
\hline
\end{tabular}




\begin{tabular}{|c|c|c|c|}
\hline & siswa & belajar & \\
\hline \multicolumn{4}{|l|}{$\begin{array}{l}\text { Kegiatan } \\
\text { Inti }\end{array}$} \\
\hline \multirow[t]{3}{*}{ Eksplorasi } & $\begin{array}{l}\text { Memancing } \\
\text { pertanyaan } \\
\text { kepada siswa }\end{array}$ & $\begin{array}{l}\text { Menanggapi } \\
\text { pertanyaan guru } \\
\text { dengan berbagai } \\
\text { jawaban }\end{array}$ & Kreatif \\
\hline & $\begin{array}{l}\text { Guru } \\
\text { memutarkan } \\
\text { slide tentang } \\
\text { siswa yang } \\
\text { merokok, anak } \\
\text { gelandangan, } \\
\text { anak pencuri, } \\
\text { kemiskinan Kali } \\
\text { Ciliwung }\end{array}$ & $\begin{array}{l}\text { Memperhatikan } \\
\text { slide sambil } \\
\text { melontarkan } \\
\text { pertanyaan terkait } \\
\text { gambar. }\end{array}$ & $\begin{array}{l}\text { Rasa } \\
\text { ingin } \\
\text { tahu, } \\
\text { toleransi, } \\
\text { peduli } \\
\text { sosial, } \\
\text { cinta } \\
\text { damai, } \\
\text { peduli } \\
\text { lingkunga } \\
\text { n }\end{array}$ \\
\hline & $\begin{array}{l}\text { Guru } \\
\text { memberikan } \\
\text { pernyataan- } \\
\text { pernyataan } \\
\text { pancingan dan } \\
\text { meminta siswa } \\
\text { mencari solusi } \\
\text { atas } \\
\text { permasalahan } \\
\text { sosial yang } \\
\text { muncul dalam } \\
\text { slide }\end{array}$ & $\begin{array}{l}\text { Menanggapi } \\
\text { pertanyaan guru } \\
\text { dan memberikan } \\
\text { solusi beragam } \\
\text { atas permasalahan } \\
\text { sosial tersebut }\end{array}$ & $\begin{array}{l}\text { Memanci } \\
\text { ng rasa } \\
\text { ingin } \\
\text { tahu, } \\
\text { peduli } \\
\text { sosial, } \\
\text { cinta } \\
\text { damai, } \\
\text { kreatif, } \\
\text { tanggungj } \\
\text { awab, } \\
\text { peduli } \\
\text { lingkunga } \\
\text { n, kerja } \\
\text { keras }\end{array}$ \\
\hline \multirow[t]{2}{*}{ Elaborasi } & $\begin{array}{l}\text { Guru } \\
\text { menggunakan } \\
\text { metode diskusi }\end{array}$ & $\begin{array}{l}\text { Siswa melakukan } \\
\text { diskusi tentang } \\
\text { materi yang sudah } \\
\text { dibagikan guru }\end{array}$ & $\begin{array}{l}\text { Mandiri, } \\
\text { tanggung } \\
\text { jawab, } \\
\text { toleransi, } \\
\text { kreatif, } \\
\text { kerja } \\
\text { keras, }\end{array}$ \\
\hline & $\begin{array}{l}\text { Guru } \\
\text { mempersilakan } \\
\text { kelompok untuk } \\
\text { presentasi tanpa } \\
\text { menunjuk }\end{array}$ & $\begin{array}{l}\text { Semua kelompok } \\
\text { berebutan untuk } \\
\text { tampil lebih dulu }\end{array}$ & $\begin{array}{l}\text { Tanggung } \\
\text { jawab, } \\
\text { mengharg } \\
\text { ai } \\
\text { prestasi, }\end{array}$ \\
\hline
\end{tabular}




\begin{tabular}{|c|c|c|c|}
\hline & $\begin{array}{l}\text { kelompok } \\
\text { tertentu }\end{array}$ & & $\begin{array}{l}\text { mandiri, } \\
\text { kreatif, } \\
\text { semangat }\end{array}$ \\
\hline & $\begin{array}{l}\text { Guru meminta } \\
\text { kelompok yang } \\
\text { lain memberikan } \\
\text { tanggapan }\end{array}$ & $\begin{array}{l}\text { Kelompok lain } \\
\text { berebutan } \\
\text { memberikan } \\
\text { tanggapan dan } \\
\text { pertanyaan }\end{array}$ & $\begin{array}{l}\text { Saling } \\
\text { menghara } \\
\text { gai, } \\
\text { tanggung } \\
\text { jawab }\end{array}$ \\
\hline Konfirmasi & $\begin{array}{l}\text { Guru bersama } \\
\text { siswa } \\
\text { memberikan } \\
\text { kesimpulan } \\
\text { Guru memuji } \\
\text { penampilan } \\
\text { semua kelompok }\end{array}$ & $\begin{array}{l}\text { Siswa secara } \\
\text { bergantian } \\
\text { memberikan } \\
\text { kesimpulan }\end{array}$ & $\begin{array}{l}\text { Mandiri, } \\
\text { tanggung } \\
\text { jawab }\end{array}$ \\
\hline $\begin{array}{l}\text { Kegiatan } \\
\text { Penutup }\end{array}$ & $\begin{array}{l}\text { Guru memberi } \\
\text { pesan moral } \\
\text { terkait dengan } \\
\text { tema yang sudah } \\
\text { di diskusikan } \\
\text { siswa Guru } \\
\text { memberikan } \\
\text { semangat agar } \\
\text { siswa lebih giat } \\
\text { belajar }\end{array}$ & $\begin{array}{l}\text { Siswa } \\
\text { mendengarkan } \\
\text { dengan baik }\end{array}$ & $\begin{array}{l}\text { Peduli, } \\
\text { mengharg } \\
\text { ai, } \\
\text { mandiri, } \\
\text { tanggung } \\
\text { jawab }\end{array}$ \\
\hline
\end{tabular}

Observasi pembelajaran IPS di kelas 4 SD N Dukuh 09, pada tahap persiapan, guru telah menyusun silabus dan RPP secara mandiri, dengan tetap mengacu pada pedoman milik pemerintah. Dalam RPP IPS, telah dicantumkan nilai-nilai karakter yang diharapkan. Guru melaksanakan tiga kegiatan yaitu, kegiatan awal, kegiatan inti, dan kegiatan penutup. Pada kegiatan awal, dicantumkan bahwa guru menyusun dan merencanakan Rencana Pelaksanaan Pembelajaran (RPP), serta menyiapkan sarana dan prasarana sebagai penunjang pembelajaran IPS.

Tabel 2. Nilai Karakter dalam pelaksanaan pembelajaran di SD Dukuh 09 Pagi

\begin{tabular}{|l|l|l|l|}
\hline Tahap & Kegiatan Guru & Kegiatan Siswa & $\begin{array}{l}\text { Nilai } \\
\text { Karakter }\end{array}$ \\
\hline $\begin{array}{l}\text { Kegiatan } \\
\text { Awal }\end{array}$ & $\begin{array}{l}\text { Guru memulai } \\
\text { dengan salam, }\end{array}$ & $\begin{array}{l}\text { Siswa } \\
\text { melaksanakan }\end{array}$ & $\begin{array}{l}\text { Religius, } \\
\text { disiplin }\end{array}$ \\
\hline
\end{tabular}




\begin{tabular}{|c|c|c|c|}
\hline & $\begin{array}{l}\text { berdo'a, dan } \\
\text { membaca surat } \\
\text { Al Fatihah }\end{array}$ & $\begin{array}{l}\text { semua kegiatan } \\
\text { tersebut dengan } \\
\text { baik dan benar }\end{array}$ & \\
\hline \multicolumn{4}{|l|}{ KegiatanInti } \\
\hline a. Eksplorasi & $\begin{array}{l}\text { Guru } \\
\text { memberikan } \\
\text { pertanyaan } \\
\text { pancingan } \\
\text { kepada siswa } \\
\text { terkait makna } \\
\text { permasalahan } \\
\text { sosial }\end{array}$ & $\begin{array}{l}\text { Terdapat tiga } \\
\text { siswa yang } \\
\text { merespon } \\
\text { pertanyaan } \\
\text { guru dengan } \\
\text { jawaban } \\
\text { bervariasi }\end{array}$ & $\begin{array}{l}\text { Rasa ingin } \\
\text { tahu, kreatif, }\end{array}$ \\
\hline b. Elaborasi & $\begin{array}{l}\text { Guru } \\
\text { memutarkan } \\
\text { slide tentang } \\
\text { permasalahan } \\
\text { sosial }\end{array}$ & $\begin{array}{l}\text { Siswa } \\
\text { membentuk } \\
\text { kelompok } \\
\text { diskusi, } \\
\text { mendiskusikan } \\
\text { tentang } \\
\text { permasalahan } \\
\text { sosial di sekitar } \\
\text { siswa }\end{array}$ & $\begin{array}{l}\text { Menghargai, } \\
\text { tanggung } \\
\text { jawab }\end{array}$ \\
\hline c. Konfirmasi & $\begin{array}{l}\text { Guru bertanya } \\
\text { jawab pada } \\
\text { masing-masing } \\
\text { kelompok } \\
\text { diskusi siswa }\end{array}$ & $\begin{array}{l}\text { Siswa } \\
\text { menanggapi } \\
\text { hasil diskusi } \\
\text { dan menjawab } \\
\text { pertanyaan } \\
\text { guru }\end{array}$ & $\begin{array}{l}\text { Rasa ingin } \\
\text { tahu, } \\
\text { menghargai }\end{array}$ \\
\hline $\begin{array}{l}\text { Kegiatan } \\
\text { Penutup }\end{array}$ & $\begin{array}{l}\text { Guru bersama } \\
\text { siswa } \\
\text { menyimpulakan } \\
\text { materi dr hasil } \\
\text { diskusi siswa }\end{array}$ & $\begin{array}{l}\text { Siswa secara } \\
\text { bergantian } \\
\text { membacakan } \\
\text { kesimpulan }\end{array}$ & $\begin{array}{l}\text { Tanggung } \\
\text { jawab }\end{array}$ \\
\hline
\end{tabular}

Pelaksanaan pembelajaran IPS kelas 4 di SD N Susukan 06 materi yang disampaikan adalah Permasalahan Sosial dan Peta. Berdasarkan hasil observasi, kegiatan awal guru yang dilakukan adalah tahap persiapan, guru menyusun silabus dan RPP dengan mencantumkan nilai-nilai karakter yang diharapkan. Pada materi pokok Permasalahan Sosial, yang tercantum dalam Kompetensi Dasar: Mengenal Permasalahan Sosial di daerahnya, guru mencantumkan nilai-nilai karakter disiplin, menghargai, 
perhatian, tekun, jujur, dan peduli. Penulisan karakter dalam RPP, merupakan langkah awal untuk melakukan implementasi pendidikan karakter dalam pembelajaran IPS. Selanjutnya, pengkajian melihat kegiatan awal, kegiatan inti, dan kegiatan penutup dalam RPP yang disusun oleh guru.

Tabel 3. Nilai Karakter dalam pembelajaran IPS di kelas 4 SD N Susukan 06

\begin{tabular}{|c|c|c|c|}
\hline Tahap & Kegiatan Guru & Kegiatan Siswa & Nilai Karakter \\
\hline $\begin{array}{l}\text { Kegiatan } \\
\text { Awal }\end{array}$ & $\begin{array}{l}\text { Guru memulai } \\
\text { dengan salam, } \\
\text { berdo'a. } \\
\text { Menyampaikan } \\
\text { materi yang akan } \\
\text { dipelajari. }\end{array}$ & $\begin{array}{l}\text { Siswa } \\
\text { melaksanakan } \\
\text { dengan baik }\end{array}$ & $\begin{array}{l}\text { Religius, } \\
\text { tanggung } \\
\text { jawab }\end{array}$ \\
\hline \multicolumn{4}{|l|}{$\begin{array}{l}\text { Kegiatan } \\
\text { Inti }\end{array}$} \\
\hline Eksplorasi & $\begin{array}{l}\text { Guru bertanya } \\
\text { jawab materi } \\
\text { minggu tentang } \\
\text { permasalahan } \\
\text { sosial dalam } \\
\text { masyarakat } \\
\text { Guru menyiapkan } \\
\text { media } \\
\text { pembelajaran }\end{array}$ & $\begin{array}{l}\text { Siswa bertanya } \\
\text { tentang materi } \\
\text { yang masih } \\
\text { belum } \\
\text { dipahami }\end{array}$ & $\begin{array}{l}\text { Teliti, } \\
\text { mandiri, } \\
\text { tanggung } \\
\text { jawab }\end{array}$ \\
\hline Elaborasi & $\begin{array}{l}\text { Guru } \\
\text { menyampaikan } \\
\text { materi yang } \\
\text { dipelajari yaitu } \\
\text { tentang peta } \\
\text { dengan } \\
\text { menunjukkan } \\
\text { gambar Peta pada } \\
\text { siswa }\end{array}$ & $\begin{array}{l}\text { Siswa } \\
\text { mendengarkan } \\
\text { dan } \\
\text { mencermati } \\
\text { gambar Peta }\end{array}$ & $\begin{array}{l}\text { Menghargai, } \\
\text { teliti }\end{array}$ \\
\hline Konfirmasi & $\begin{array}{l}\text { Guru bertanya } \\
\text { jawab dengan } \\
\text { siswa tentang } \\
\text { materi yang } \\
\text { belum jelas }\end{array}$ & $\begin{array}{l}\text { Siswa } \\
\text { menjawab } \\
\text { pertanyaaan } \\
\text { dari guru }\end{array}$ & $\begin{array}{l}\text { Tanggung } \\
\text { jawab }\end{array}$ \\
\hline $\begin{array}{l}\text { Kegiatan } \\
\text { Penutup }\end{array}$ & $\begin{array}{l}\text { Guru } \\
\text { menyimpulkan } \\
\text { dan }\end{array}$ & $\begin{array}{l}\text { Siswa } \\
\text { mendengarkan }\end{array}$ & $\begin{array}{l}\text { Menghargai, } \\
\text { mandiri }\end{array}$ \\
\hline
\end{tabular}




\begin{tabular}{|l|l|l|l|}
\hline & $\begin{array}{l}\text { menyampaikan } \\
\text { pelajaran minggu } \\
\text { depan }\end{array}$ & & \\
\hline
\end{tabular}

\section{Kendala Yang Dihadapi Guru}

Dalam implementasi nilai-nilai karakter pada pembelajaran IPS menurut guru kelas IV di SDS PB Soedirman, menjelaskan bahwa secara umum dalam mengimpelementasikan nilai-nilai karakter dalam pembelajaran tidak begitu sulit, karena guru dengan mudah mengaitkan materi IPS dengan nilai-nilai karakter dalam masyarakat.

Kendala-kendala yang dihadapi oleh guru di kelas adalah dalam penentuan nilai sikap masih belum adanya aturan yang baku, artinya dalam memberikan nilai, sikap dan perilaku siswa masih belum maksimal. Tentu saja atas kesadaran dan kemauan guru dalam mengembangkan karakter dan kepribadian siswa seperti yang diharapkan.

Dalam pembelajaran IPS di kelas 4 SD N Dukuh 09 guru tidak merasa kesulitan untuk menyampaikan materi IPS yang diintegrasikan dengan nilai karakter. Kendala guru adalah dalam membuat Rencana Pelaksanaan Pembelajaran (RPP) yang berkarakter belum menemukan contoh yang baku dari pemerintah. RPP berkarakter yang dikembangkan sekarang masih terdapat format yang berbeda-beda, hal itu membuat bingung guru dalam membuat RPP. Selain itu, kendala yang dihadapi guru dalam pembelajaran adalah proses evaluasi atau penilaian sikap masing-masing siswa yang terkadang tidak terdokumentasi oleh guru.

Kendala yang sering dihadapi guru kelas 4 SD Susukan 06 adalah dalam hal evaluasi proses pembelajaran, evaluasi dilakukan guru hanya sekedar tes tertulis yang bersifat kognitif saja. Seharusnya ada penilaian sikap yang secara kontinyu 
dilakukan oleh guru untuk melihat perkembangan perilaku siswa. Selain itu, belum adanya koordinasi yang maksimal antara kepala sekolah, guru dan juga orang tua. Komunikasi yang efektif harus dilakukan antara berbagai pihak terutama dengan orang tua siswa, karena orang tua juga berperan mengembangkan karakter anak.

Dari hasil penelitian, pendidikan karakter masih dipahami dan ditanggapi secara berbeda oleh guru. Meskipun ketiga guru menyepakati bahwa pendidikan karakter adalah upaya menanamkan nilai moral kepada siswa, ada perbedaan pandangan terkait integrasi pendidikan karakter dalam mata pelajaran. Dari tiga sekolah yang diteliti, dua guru berkesimpulan bahwa pendidikan karakter tidak sekedar diintegrasikan dalam mata pelajaran Pendidikan Kewarganegaraan, Pendidikan Agama, dan Pendidikan IPS, tetapi seluruh mata pelajaran harus menyertakan upaya penanaman nilai karakter. Sedangkan satu guru menyatakan bahwa pendidikan karakter hanya bisa diajarkan dalam ketiga mata pelajaran yang berkaitan dengan sosial dan moral, mata pelajaran lain terutama tentang sains dan matematika tidak bisa memasukkan pendidikan karakter dalam pengajarannya.

Perbedaan pandangan ketiga guru tersebut tidak lepas dari latar belakang ketiga guru yang diteliti. Pertama, latar belakang pendidikan guru. Dua guru yang memiliki pemahaman sama tentang pendidikan karakter, berasal dari sarjana pendidikan, sedangkan guru yang memahami pendidikan karakter hanya diajarkan dalam mata pelajaran moral dan sosial merupakan sarjana non kependidikan. Kedua, faktor lingkungan sekolah. Dua guru mengajar di lingkungan sekolah yang bertaraf Rintisan Sekolah Berbasis Internasional dengan Sekolah Standar Nasional. 
Hal ini jelas terlihat perbedaannya, dua guru di sekolah RSBI sudah lebih banyak mengimplementasikan nilai-nilai karakter di setiap pembelajaran terutama IPS, tetapi 1 guru dari Sekolah SN belum mengimplementasikan nilai-nilai karakter dalam setiap pembelajaran.

Selain pemahaman tentang integrasi pendidikan karakter dalam mata pelajaran, guru juga menyatakan bahwa pendidikan karakter dapat dilakukan melalui dua tahap, yaitu:

1. Keteladanan

Keteladanan sebagai penanaman pendidikan karakter dipahami sebagai upaya seluruh warga sekolah, terutama kepala sekolah dan guru, untuk bertutur kata dan bertingkah laku yang sesuai dengan norma dan tata tertib sekolah.

2. Pembiasaan

Tahap ini adalah upaya penanaman nilai karakter secara aplikatif, konsisten, tegas, dan terus menerus ke diri siswa. Tahap ini merupakan upaya pembentukan habit (perilaku) siswa agar tidak terjadi kontradiksi antara kehidupan siswa di sekolah dan di rumah. Tahap ini menurut guru adalah yang paling sulit, terutama ketika harus berbenturan dengan kondisi di keluarga dan masyarakat tempat siswa bersosialisasi.

Langkah yang sudah dilakukan guru adalah melalui pembiasaan, misalnya ketika di dalam kelas ada beberapa siswa yang tidak sesuai aturan (ramai, menggangu temannya, tidak memperhatikan, dsb) kemudian secara langsung guru menegur dan memberikan arahan untuk berbuat baik.

Kedua tahap yang dipahami guru sebagai upaya penanaman pendidikan karakter, membuktikan bahwa pemahaman guru terhadap penanaman pendidikan karakter tidak bisa parsial. Pendidikan karakter harus dilakukan secara komprehensif dan 
membutuhkan kerjasama antara warga sekolah dengan keluarga. Pendidikan karakter sebaiknya tidak hanya menjadi tanggungjawab mata pelajaran Agama, Pendidikan Kewarganegaraan, dan pendidikan IPS, tetapi semua elemen sekolah memiliki kewajiban mengupayakan pendidikan karakter dalam setiap waktu dan kesempatan.

Jadi, dalam mengimplementasikan nilai-nilai karakter dalam pembelajaran khususnya mata pelajaran IPS, guru harus membuat beberapa tahapan pembelajaran. Tahapan-tahapan pembelajaran dapat dilakukan 3 langkah, dimulai dari plan (perencanaan) yang dituangkan dalam RPP, kemudian do (melakukan) dari apa yang sudah direncanakan dan reflection (mengevaluasi) dari hasil pembelajaran.

\section{Simpulan}

Implementasi pendidikan karakter dalam mata pelajaran IPS sudah berjalan dengan baik meskipun belum secara benar. Ini terkait dengan pemahaman guru mengenai pendidikan karakter yang telah sesuai dengan pengertian pendidikan karakter menurut Pusat Kurikulum dan Perbukuan. Pendidikan Karakter dipahami guru sebagai upaya untuk menanamkan nilai moral kepada peserta didik. Tetapi dari segi implementasi dalam kegiatan pembelajaran, ada perbedaan dalam mengintegrasikan nilai karakter dalam mata pelajaran IPS. Namun, mayoritas guru mengintegrasikan niai karakter secara spontanitas, insidental (tidak direncanakan).

Kendala guru adalah minimnya pengetahuan dan kompetensi menyusun RPP berkarakter. Hal ini memicu tidak maksimalnya integrasi pendidikan karakter dalam pelaksanaan kegiatan pembelajaran. Kendala selanjutnya adalah komunikasi yang kurang baik antara sekolah dan pihak orang tua. Seringkali pihak 
orang tua tidak memberikan respon atas feed back yang diberikan guru kepada anak ketika di kelas. Hal ini berpengaruh pada sulitnya guru dalam mengukur seberapa besar kemampuan siswa dalam menyerap nilai-nilai karakter yang diajarkan di kelas.

\section{Saran}

a. Untuk guru, perlu:

1) Mempelajari dengan baik dan benar tentang konsep pendidikan karakter

2) Mempelajari metode yang digunakan untuk mengintegrasikan nilai karakter dalam pembelajaran IPS

3) Memahami secara mendalam kondisi siswa, materi, tujuan belajar, sehingga dapat mengaitkan dan memprioritaskan nilainilai karakter yang hendak diintegrasikan

4) Mempelajari cara penyusunan RPP berkarakter dan benar-benar mengaplikasikanya dalam setiap kegiatan pembelajaran

5) Mengintegrasikan pendidikan karakter dalam semua materi mata pelajaran IPS, tidak hanya yang terkait dengan materi sosial saja.

b. Untuk Kepala Sekolah, perlu:

1) Memfasilitasi guru untuk belajar dengan baik dan benar mengenai konsep dan metode pelaksanaan pendidikan karakter

2) Mengkondisikan lingkungan sekolah yang mendukung terciptanya implementasi pendidikan karakter di kelas dan sekolah.

3) Menjembatani komunikasi guru dan orang tua murid agar tercipta hubungan yang baik demi kebaikan peserta didik 


\section{Daftar Pustaka}

Barth, James. L. (1990). Methods of instruction in social studies education. New York: University Press of America.

Darmiyati Zuhdi. (2008). Humanisasi pendidikan: menemukan kembali pendidikan yang manusiawi. Jakarta: Bumi Aksara.

Depdiknas. (2003). Undang-Undang RI Nomor 20, Tahun 2003, tentang Sistem Pendidikan Nasional.

Ellis. A.K. (1997). Teaching and learning elementary social studies. Boston: Allyn \& bacon A Viacom Company.

Lickona, T. (1992). Educating for character, how our schools can teach respect. respect and responsibility. New York: Bantam Books.

National Council for Social Studies (NSCC). 15 Juli 2006. About NCSS. Diambil pada tanggal 10 Desember 2009, dari http://en.wikipedia.org/wiki/National_Council_for_the_Soci al_Studies

Ryan, K., \& Bohlin, K. E. (1999). Building character in schools: Practical ways to bring moral instruction to life. San Fransisco, CA: Jossey-Bass.

Sardjiyo. (2007). Pendidikan IPS di SD. Jakarta: Universitas Terbuka.

Suwaeman al Muchtar. (1991). Pengembangan kemampuan berpikir dan nilai dalam pedidikan IPS (Suatu Studi Budaya Pendidikan). Disertasi doktor, tidak diterbitkan, Universitas Negeri Yogyakarta, Yogyakarta

Sutopo. (2006). Metode Penelitian Kualitatif. Surakarta. UNS Press.

Tadkiratun Musfiroh. (2008). Character building. Yogyakarta: Tiara Wacana. 